\title{
La desvirtualización del concepto reputación en el entorno virtual
}

\author{
Dra. Magdalena Mut Camacho \\ Universitat Jaume I
}

En la actualidad el uso del concepto reputación online aplicado a la comunicación de la empresa en el entorno virtual lo ha llevado a una auténtica alteración de su significado, a la degradación por el mal uso del término y a la desvirtualización de su carga teórica. Se ha visto desnaturalizado de tal modo que ha llegado a convertirse en un concepto banal e insípido.

La convergencia entre el auge de las nuevas tecnologías vinculadas a la comunicación corporativa ha favorecido el nacimiento de lo que se ha venido llamando la reputación online. La aparición de todas estas posibilidades tecnológicas ha mejorado la comunicación de la empresa y la ha dotado de magníficas posibilidades para su desarrollo en la consecución de una auténtica relación próxima e interactiva con sus stakeholders.

Sin embargo, lejos de la visión teórica de lo que es reputación corporativa, vemos como en muchos casos se sustenta la reputación online en concepciones reduccionistas sobre motores de búsqueda o análisis de opiniones en las redes sociales. Por tanto, entender la gestión de la reputación como acciones de SEO (Search Engine Optimization), SEM (Social Engine Marketing), monitorizaciones online, opiniones personales, opiniones en blogs, redes sociales, etc. son acciones poco rigurosas con el concepto reputación y su importancia estratégica para la empresa. Se ha de entender que la detección de opiniones en Internet o el posicionamiento web de la compañía, dista muchísimo de lo que es reputación corporativa. 
De forma exhaustiva, deberíamos entender lo que se conoce como reputación online como algo consustancial a la reputación corporativa y, por tanto, debe ser gestionada con los mismos indicadores, ni desagregada a ésta.

La incidencia de las redes sociales en la reputación ha abierto un doble camino: por un lado, como ya se ha apuntado, las relaciones corporativas se pueden hacer más estrechas y fructíferas; y, por otro, la gestión tradicional de la marca pasa de recaer exclusivamente en la empresa, a recaer en el resto de los públicos. Facebook, por ejemplo, genera un diálogo entre clientes, de forma que la marca deja de ser gestionada únicamente por la empresa y son todos los consumidores los que se sienten implicados, hablan de ella, participan y se hacen fans incluso.

El entorno virtual es un lugar, una herramienta de comunicación, donde se construye valor de marca, donde se participa y se promueve conversación, pero todo esto es parte de la reputación corporativa.

La reputación corporativa es confianza, es el reconocimiento que los stakeholders hacen de la organización en función del cumplimiento de su compromiso, teniendo en cuenta el comportamiento corporativo, la cultura y la marca, como elementos que intervienen. Conseguir reputación corporativa, o lo que es lo mismo, ser reconocidos de forma continuada y estable en el tiempo, es un gran activo para la organización. La reputación corporativa depende de las siguientes variables (Villafañe, 2006: 20) los resultados económico-financieros, la fortaleza de su oferta comercial, las políticas y comportamientos en la gestión del capital humano, la sostenibilidad, la responsabilidad social corporativa, la innovación, todas ellas son solidarias con la creación de la confianza.

La reputación corporativa es la expresión de esta armonía entre todas estas dimensiones de la empresa, donde están implicados todos sus valores tangibles y los intangibles de forma amplia y desde todos los ángulos, también el de su dimensión online, pero sin desagregarlo, sin desvirtuar el concepto reputación.

La comunicación online también forma parte de la reputación corporativa, su gestión ha de ser complementaria y acorde. Su importancia es incuestionable porque su valor es importantísimo si se enmarca dentro de una estrategia oportuna, clara y coherente con los objetivos corporativos enmarcados en una firme identidad corporativa.

El mundo de lo online ha abierto muchas perspectivas nuevas en la gestión de la organización, entre ellas la gestión de la reputación corporativa, pero no debe caer en el concepto hueco. Debemos reflexionar y comprender que como herramienta de comunicación, lo online, ha de gestionarse desde la coherencia de la identidad corporativa, en sinergia y con sensatez. 


\section{Referencias}

Aced, C. (2010). Visibilidad. Cómo gestionar la reputación en Internet. Barcelona: Gestión 2000.

Fombrun, Ch. y Van Riel, C. (2003). Fame \& Fortune. How susscessful companies buld winning reputations. Prentice Hall.

Villafañe, J. (2006). Quiero trabajar aquí. Seis claves de la reputación interna. Madrid: Pearson Prentice Hall.

Villafañe, J. (2011). La comunicación empresarial y la gestión de intangibles en España y Latinoamérica. Madrid: Pearson.

\section{Referencia de este artículo:}

Mut Camacho, Magdalena (2012). La desvirtualización del concepto reputación en el entorno virtual. En: adComunica. Revista Científica de Estrategias, Tendencias e Innovación en Comunicación, $\mathrm{n}^{\circ} 3$. Castellón: Asociación para el Desarrollo de la Comunicación adComunica, Universidad Complutense de Madrid y Universitat Jaume I, 227-229. DOI: http://dx.doi.org/10.6035/21740992.2012.3.18 